\title{
Lethal Hemorrhage Induced by A Pet Cat Scratch on Varicose Veins
}

\author{
C. Apostolidou ${ }^{1, *}$, T. Koletsa ${ }^{2}$, F. Chatzinikolaou ${ }^{1}$, D. Psaroulis ${ }^{1}$, S. N. Njau ${ }^{1}$ and I. Kostopoulos ${ }^{2}$ \\ ${ }^{1}$ Department of Forensic Medicine \& Toxicology, Medical School, Aristotle University of Thessaloniki, Greece \\ ${ }^{2}$ Pathology Department, Medical School, Aristotle University of Thessaloniki, Greece
}

\begin{abstract}
This report details the case of a 76-year old woman who was found dead at her home in a pool of blood after suffering leg injury by her pet cat. A claw was found on her trauma. Veterinary examination verified that the claw belonged to her cat. Macroscopic and microscopic findings confirmed that the victim was suffering from varicose veins in the lower limbs.

Though the death scene suggested that a crime had taken place, a thorough investigation demonstrated that the cause of death was bleeding from the ruptured varicose veins.
\end{abstract}

Keywords: Varicose veins, lethal hemorrhage, cat scratch.

\section{INTRODUCTION}

Varicose veins are abnormally dilated and tortuous veins, caused by increased venous pressure or disease of the venous wall. Virtually any veins can be affected but the superficial leg veins are most frequently involved because of the increased venous pressure there. Venous pressure in the legs, when standing, is approximately five times that during recumbency [1].

It is estimated that 10 to $20 \%$ of the general population eventually develop this disorder in the course of life. It is much more common in the age groups over 50, in which the incidence may reach a figure of $50 \%$ of individuals. Over the age of 30 , females are affected four times more commonly than males, a reflection of the venous stasis in the lower legs caused by pregnancy. In younger individuals there is no striking sex preponderance [2].

The superficial veins of the legs lie unsupported in loose subcutaneous tissue, and in normal circumstances are merely subsidiary. Between the superficial and deep systems, however, are several communicating channels, notably at the saphenous opening and at the poptiteal space. In conditions in which the pressure in the deep veins is raised these communicating channels transmit the excess blood to the superficial system, which thus becomes a temporary receptacle for the excess blood $[3,4]$.

In sedentary persons gravitation affects a passive venous congestion of the whole limb. The deep veins being surrounded by muscles are well supported, and transmit the increased pressure to the superficial veins, and there, being unsupported, dilate $[3,4]$.

Adjacent portions of a tortuous vein may become bound together by fibrous tissue and are often closely adherent to

*Address correspondence to this author at the Aristotle University of Thessaloniki, Medical School, Forensic Medicine \& Toxicology Department, University Campus, 54006 Thessaloniki, Greece;

Tel: +302310999236; E-mail: filkont@yahoo.com the skin, which itself ultimately undergoes atrophic changes. Stasis of blood in the veins and congestion in the perivascular tissues lead to the deposition of haemosiderin, and when the veins lie close to the surface, as on the medial surface of the leg, the skin may become deeply pigmented [3].

The effects of varicose veins (of whatever cause) are characteristic. The veins dilate, increase in length and become tortuous and often sacculated. The vessel wall becomes thickened by fibrosis and its muscle fibers atrophy, with the result that the vessel when cut or ruptured gapes widely, permitting free and sometimes fatal hemorrhage [3].

While the complications of varicose veins (leg edema, varicose eczema and ulceration), are not unusual, fatal hemorrhage from rupture is a rare event in most forensic practices $[5,6]$. It has been estimated that such deaths account for $<0.01 \%$ of coroner's cases [7]. The investigation of cases is usually straightforward, although the amount of blood at the scene, and the elderly and frail nature of many of the victims may raise the possibility of an assault [8].

\section{CASE REPORT}

\subsection{Case History}

A 76-year old woman was found dead at her apartment, where she lived alone. A friend who visited her, knocked the door without response and finally managed to enter after calling a technician, who opened the door. She was found lying in a pool of blood (Fig. 1). The police were informed and arrived immediately at the scene. The scene investigation revealed a pet cat that was present in the apartment. Answering the police questions, the descedent's friend stated that she had seen her the previous evening and the deceased was generally in good health. A distant relative with whom the police came in contact reported no recent communication with the deceased. Medical records were not found.

Scene investigation revealed evidence of extensive hemorrhage with patterns of finely clustered blood stains on the 


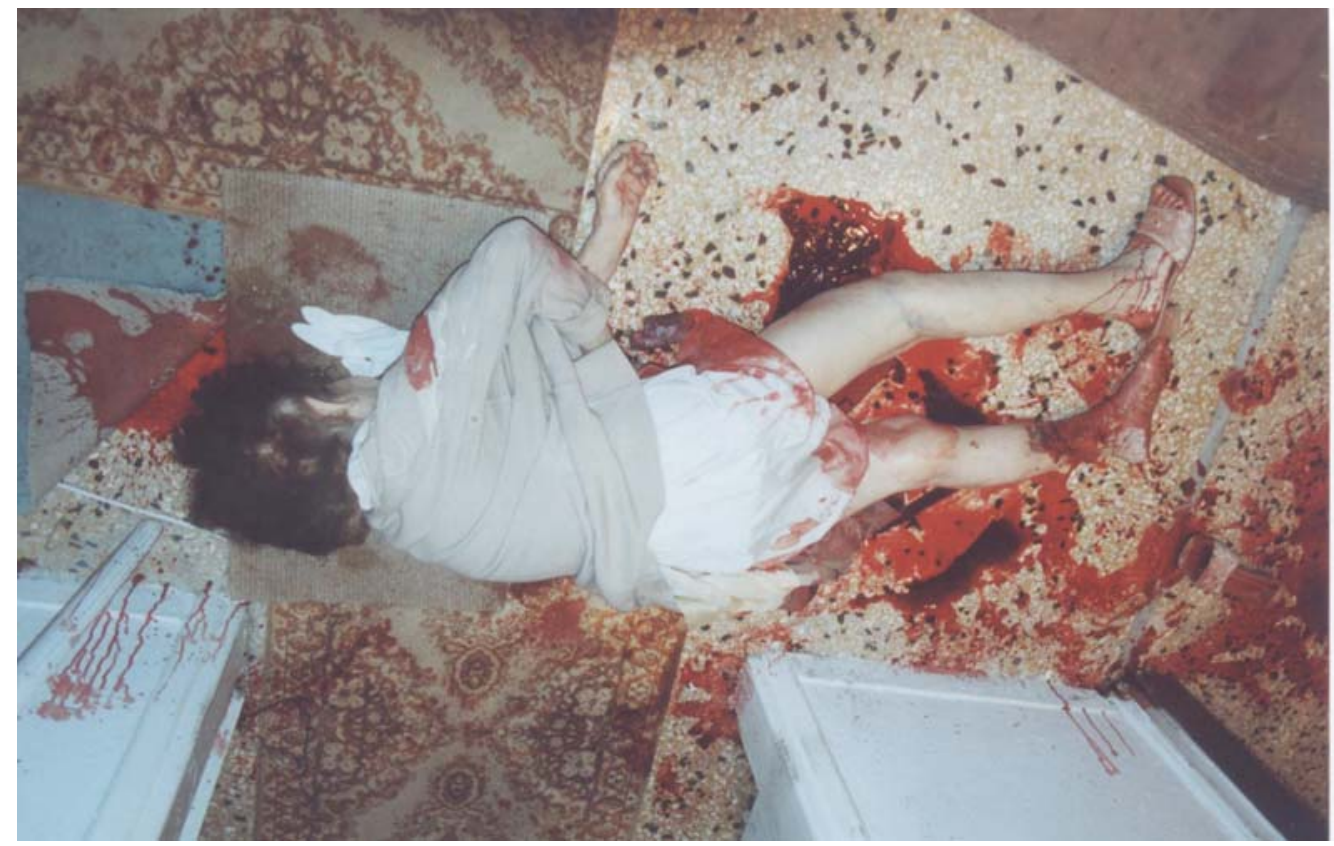

Fig. (1). The position in which the victim was found.

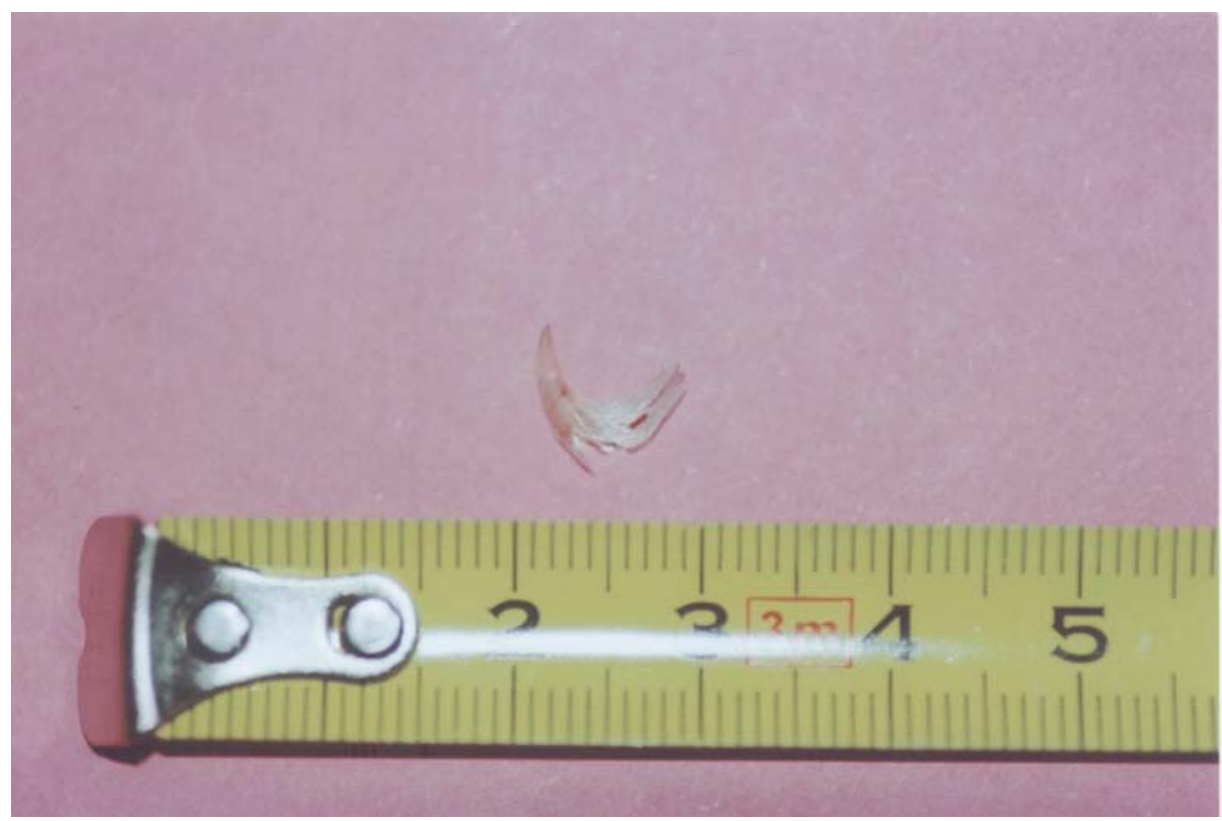

Fig. (2). The claw at the scene.

floors and walls of the bathroom, the bedroom and the corridor, where the body lied. Blood covered the body from the waist to the lower extremities. The pattern and distribution of bloodstains was characteristic of the release of blood under pressure, as in arterial hemorrhage. The deceased was in state of rigor mortis with grasped keys and morsels of meat in her hands.

\subsection{Autopsy Findings}

The decedent was that of well-nourished woman about 76 years of age. Two oblong traumas at the inferior surface of the left leg, above the malleolus, were observed, measured in length 2.5 and $1.2 \mathrm{~cm}$ respectively. At the posterior surface of the right leg, $7 \mathrm{~cm}$ above the Achillies tendon, a claw was located (Fig. 2). At the region of the traumas the venous system was dilated and a palm-sized skin discoloration was present (Fig. 3).

The traumas were still bleeding during the autopsy, although it was performed 15 hours later. No other significant injuries were present and there were no areas of arterial trauma.

On internal examination, there was a mild atheromatosis at the arteries of the brain, the heart and the kidneys but otherwise the organs of the body were found to be normal in 
appearance for a woman of this age. There was a generalized ischemia of internal visceral organs.

\section{MATERIALS AND METHODS}

\subsection{Materials}

The claw and the pet cat were given to the Veterinary Clinic of the local University.

A specimen from the skin lesions was sent for histological examination. The dimensions of the specimen were $5.1 \times 5.5 \mathrm{~cm}$ and the depth, including the subcutis, was 1.2 $\mathrm{cm}$. At the epidermis two oblong traumas were observed, measured in length $1.9 \mathrm{~cm}$ and $0.9 \mathrm{~cm}$ respectively.

\subsection{Histological Examination}

The specimen was fixed in $10 \%$ formalin and embedded in paraffin block. $5 \mu \mathrm{m}$ sections were stained with hematoxylin-eosin for light microscopy.

\subsection{Immunohistological Examination}

Immunohistochemistry was performed using a standard streptavidin-biotin method. Immunostains for CD34 antigen and smooth muscle actin (SMA) were applied.

\section{RESULTS}

The veterinary examination demonstrated that the claw belonged to the pet cat. According to the report, the cat became aggressive when its tail was touched. Otherwise its behavior was normal.

Histological examination revealed a fissure of the epidermis and dermis, ending in a cavity which was considered to be a dilated vein with ruptured wall (Fig. 4). In the dermis hemorrhagic perfusion was observed. Vessels with thrombi in their lumina were also found.

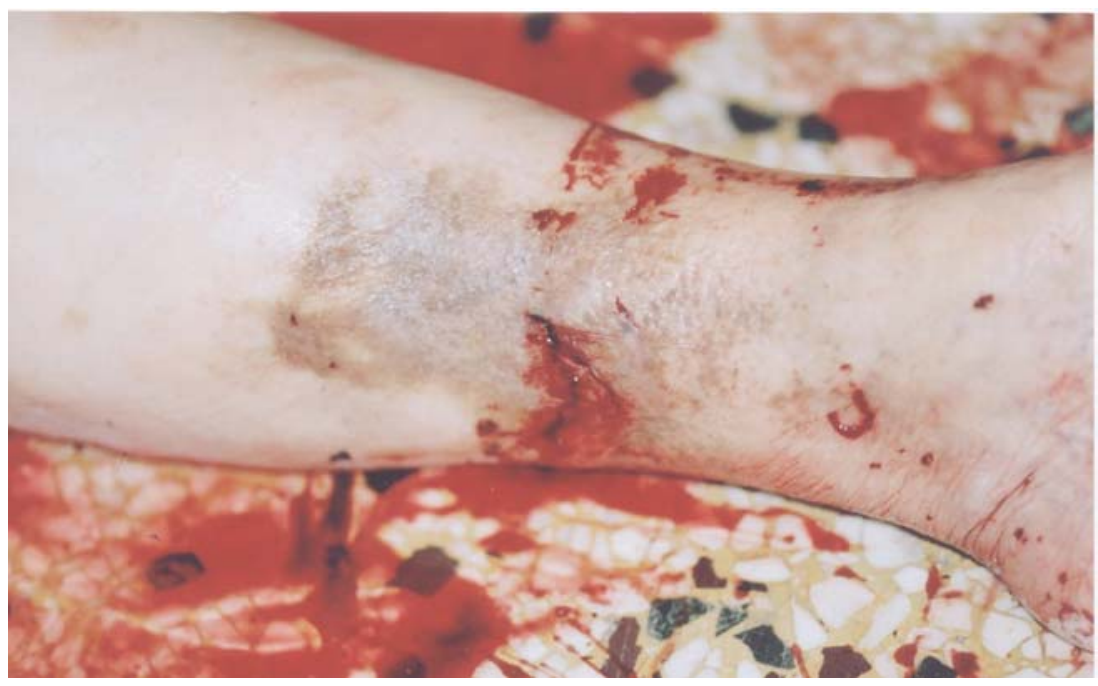

Fig. (3). Discoloration of the skin.

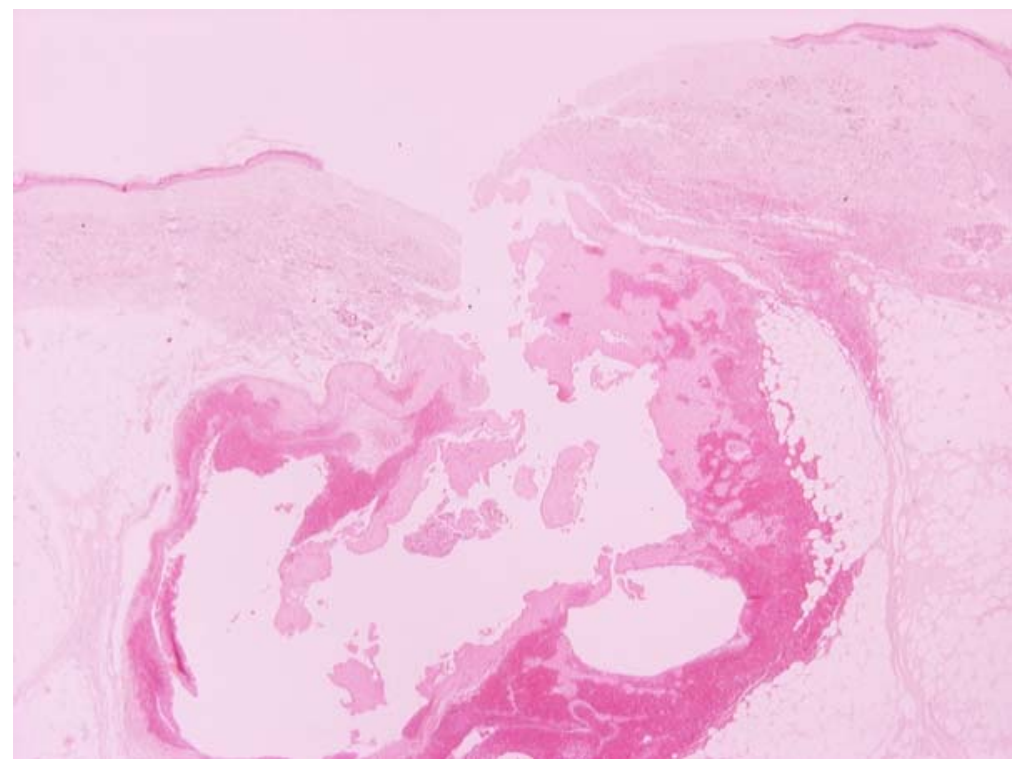

Fig. (4). Loss of continuity of the epidermis and dermis. A ruptured cystic space in the dermis is observed [HE x200]. 
Immunostains for CD34 antigen and SMA confirmed the presence of dilated vessels with ruptured wall located in the dermis and accompanied by hemorrhagy (Figs. 5, 6).

\section{DISCUSSION}

The lower extremities provide a higher stress than the upper extremities for the venous walls in the human being due to the greater hydrostatic pressure. There are two types of veins in the legs: one system provides the backflow at the surface of the leg, and the other in the depth of the leg. Both systems are connected by the perforating or communicating veins. A mechanism that supports the backflow in the veins is referred to as the "muscle pump". When moving leg muscles the blood in the nearby veins is prevented from flowing back by the anatomical proximity of muscles and veins [9].

In patients with varicosities, the venous system of the legs shows dysfunction. The veins are widened and the venous valves leak. This causes the surface veins to show more clearly and larger through the skin. The deeper veins often show dysfunction in thrombosis. Faulty valves in the saphenous vein in the legs are often the cause of varicose vein problems [9].

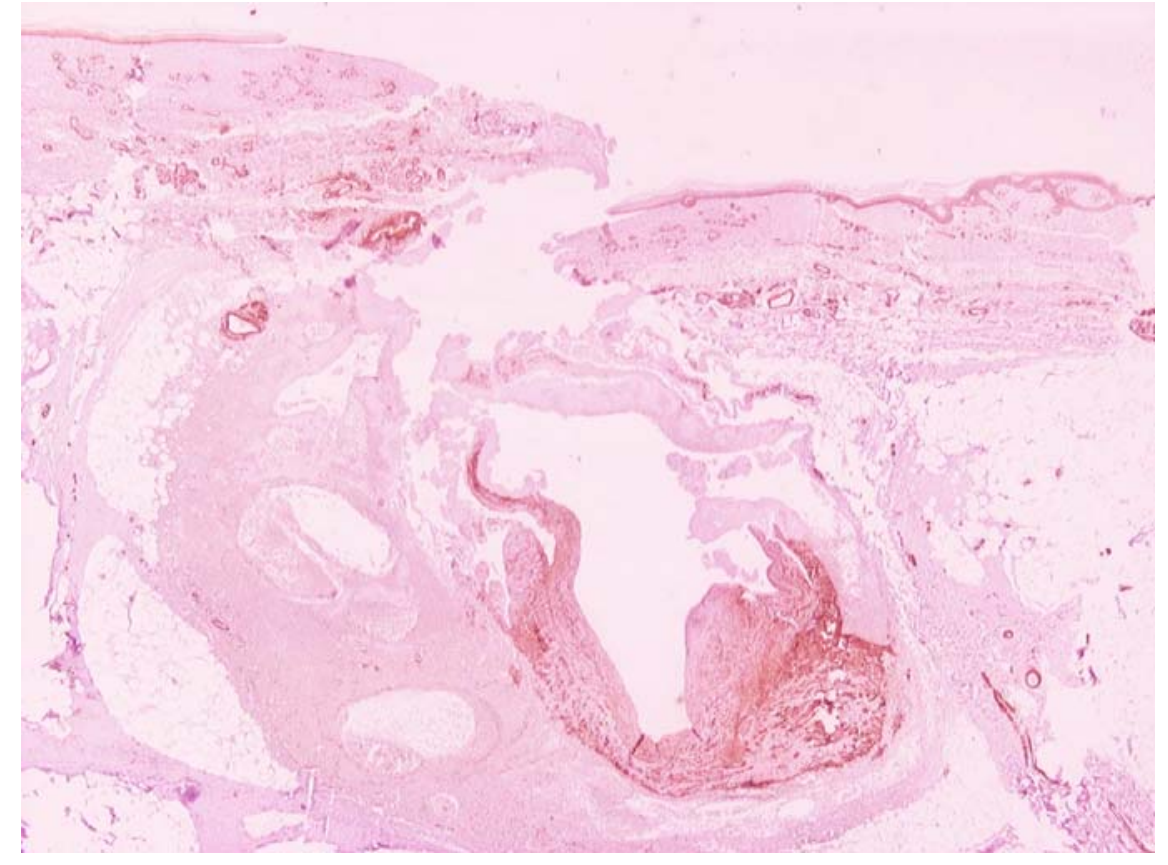

Fig. (5). Immunostain with SMA revealed the wall of a dilated vessel [SMA x200].

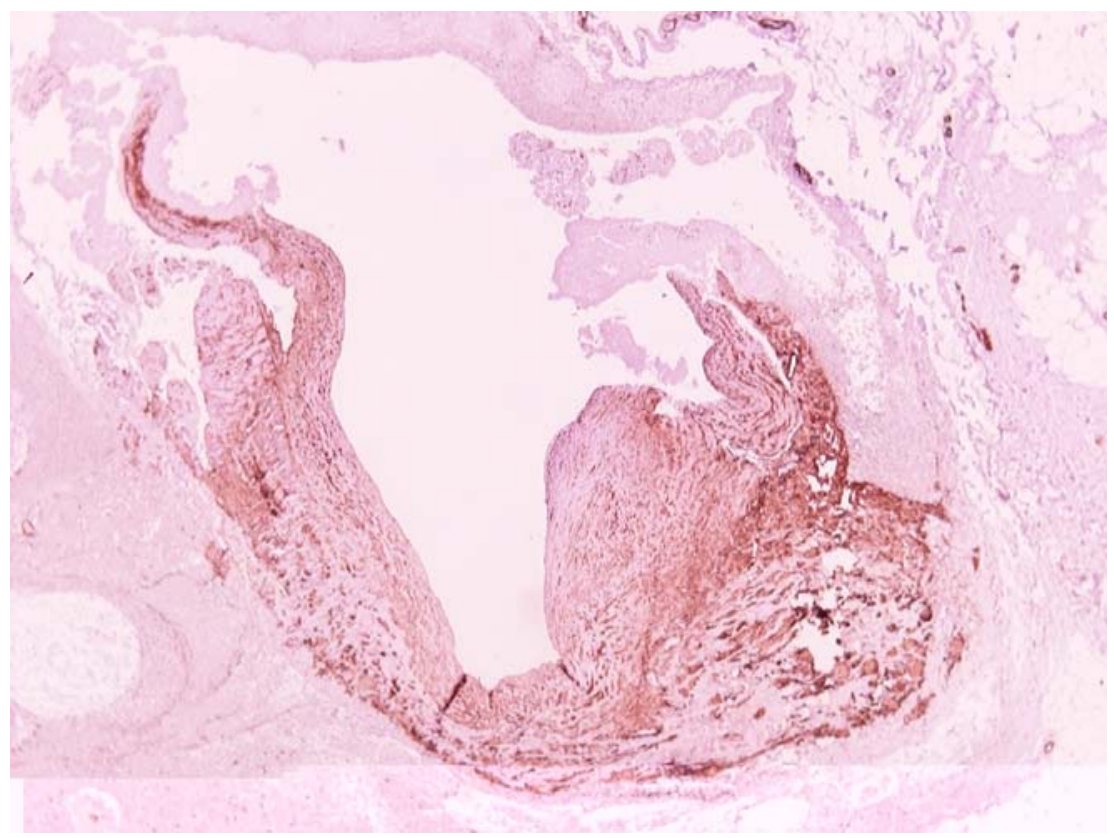

Fig. (6). Smooth muscle fibres in the vein's wall [SMA x400]. 
Illnesses of the surface and deeper venous system can lead in the long term to a chronic venous insufficiency syndrome. This condition shows often changes in the skin of these areas and can lead to ulceration and serious hemorrhage. Because of the changes in the skin and the fragility of the damaged veins in combination with the high pressure in the lower limbs, these patients can develop active hemorrhage with minor scratches or injuries to the skin. Often these bleeding events do not cause any pain or sensation and are noticed by the individual only through the release of blood [9].

Death due to hemorrhage from rupture peripheral varicose vein is an uncommon event $(0.01 \%)$. The male to female ratio was $1: 3$, with an age range of 58-84 years (mean $=78$ years). All the victims located at their home addresses, where they had been alone at the time of their deaths. Scene investigation revealed considerable blood loss, with pooling around the victim's bodies and also in other parts of the house particularly the bathroom/toilet area [7].

In our case the only information we have about the condition of the deceased were that of her friend, who was visiting the victim almost every evening. According to her report the victim was in good health and didn't take any medication.

According to police investigation no medical records or medicines were found. Examination of the rest of the house gave no information of an outside intruder. Another important observation was the fact that all of the projected bloodstains found on furniture and walls localized at a height level that could be observed after vascular injury.
According to all these above we came to the conclusion that death was attributed to exsanguination from a ruptured varicose vein of the left leg with underlying mild coronary artery atherosclerosis.

\section{ACKNOWLEDGMENTS}

The authors wish to express thanks to the Principal of the Pathologic Clinic of Pet Animals, Prof. Koutina A. F.

\section{REFERENCES}

[1] Roderick, A.C.; Alexander, W.M.; Peter, B.M.; Ghazi, S.Z. In Pathology, The Mechanisms of Disease, 2nd ed.; Mosby C.V. St.; Louis, 1989, p. 207.

[2] Robbins, S.L.; Cotran, R.S. In Pathologic Basis of Disease, 2nd ed.; Saunders W.B. Philadelphia, 1981, p. 629.

[3] Illingworth, C.; Dick, B.M. In A Texbook of Surgical Pathology, 10th ed.; J. \& A. Churchill LTD: London, 1968, p. 245.

[4] Schwartz, I.S.; Lillehei, C.R.; Shires, G.T.; Spencer, C.F.; Storer, H.E. In Principles of Surgery, 2nd ed.; McGraw Hill: Blakiston Publication, 1974, pp. 925-926.

[5] Racette, S.; Sauvageau, A. Unusual sudden death. Two case reports of hemorrhare by rupture of varicose veins. Am. J. Forensic Med. Pathol. 2005, 26, 294-6.

[6] Morrow, P.L.; Hardin, N.J.; Karn, CM; Beloin, R.; McDowell, R.W. Fatal hemorrhage caused by varicose veins. Am. J. Forensic Med. Pathol., 1994, 15, 100-4.

[7] Byard, RW.; Gilbert, J.D. The incidence and characteristic features of fatal hemorrhage due to ruptured varicose veins - a 10 year autopsy study. Am. J. Forensic Med. Pathol., 2008, 28, 299302.

[8] Byard, R.W.; Veldhoen, D.; Manock, C.; Gilbert, J.D. Blood stain pattern interpretation in cases of fatal hemorrhage from ruptured varicose veins. J. Forensic Legal Med., 2007, 14, 155-158.

[9] Silke, M.C.; Brodbeck, M.D. Reflections upon Arteries and Veins - A Plea for "Spurt Patterns". I.A.B.P.A. Newsletter. June 2007, pp. 4-14. http://www.iabpa.org/June 2007 final.pdf

Received: January 06, 2010

Revised: January 22, 2010

Accepted: January 23, 2010

(C) Apostolidou et al.; Licensee Bentham Open.

This is an open access article licensed under the terms of the Creative Commons Attribution Non-Commercial License (http://creativecommons.org/licenses/by-nc/3.0/) which permits unrestricted, non-commercial use, distribution and reproduction in any medium, provided the work is properly cited. 